\title{
Efficiency Improvement of a Natural Gas Marine Engine Using a Hybrid Turbocharger
}

\author{
Marco Altosole ${ }^{1}$, Giovanni Benvenuto ${ }^{1, *}$, Ugo Campora ${ }^{2}$, Federico Silvestro ${ }^{1}$ (iD and \\ Giulio Terlizzi ${ }^{1}$ \\ 1 Dipartimento di Ingegneria Navale, Elettrica, Elettronica e delle Telecomunicazioni (DITEN), \\ University of Genoa, Via Montallegro 1, I-16145 Genova, Italy; marco.altosole@unige.it (M.A.); \\ federico.silvestro@unige.it (F.S.); giulio_terlizzi@hotmail.it (G.T.) \\ 2 Dipartimento di Ingegneria Meccanica, Energetica, Gestionale, Trasporti (DIME), University of Genoa, \\ Via Montallegro 1, I-16145 Genova, Italy; campora@unige.it \\ * Correspondence: giovanni.benvenuto@unige.it; Tel.: +39-010-353-2436
}

Received: 30 June 2018; Accepted: 20 July 2018; Published: 24 July 2018

\begin{abstract}
The use of a computer simulator, previously developed and validated, applied to a four-stroke marine dual-fuel engine, has allowed the authors to present in this paper a solution to improve the overall efficiency of the engine by adopting a hybrid turbocharger. This component replaces the original one allowing, in addition to maintaining the previous usual functions, the production of electricity to satisfy part of the ship's electric load. In this study the application of the hybrid turbocharger concerns an engine powered by natural gas in particular. The turbocharger substitution involves a significant variation of the engine load governor operating mode. The improved engine characteristics that the hybrid turbocharger facilitates, compared to the original, are highlighted by the results reported in tabular and graphical form, for different engine loads and speeds.
\end{abstract}

Keywords: simulation; natural gas marine engine; hybrid turbocharger

\section{Introduction}

In the shipping world, in recent years, increasingly restrictive regulations have been issued by the International Maritime Organization (IMO) on the polluting emissions of nitrogen oxides $\left(\mathrm{NO}_{\mathrm{x}}\right)$ and sulfur oxides $\left(\mathrm{SO}_{\mathrm{x}}\right)$ into the atmosphere (see IMO Tier II and III, ECA world areas [1,2]). At the same time, the issue of reducing carbon dioxide $\left(\mathrm{CO}_{2}\right)$ emissions from ships has also become crucial, in relation to the problem of controlling the greenhouse effect on the planet. In this regard the Energy Efficiency Design Index (EEDI) [3-5] introduced by IMO foresees increasing restrictions on carbon dioxide emissions in the coming years. To meet these regulatory constraints, the ships in question must increase the energy conversion efficiency of on-board systems based on propulsion engines and diesel-electric generators and properly manage their respective operations [6].

Marine diesel engines, by far the prime mover most used in ship propulsion systems, are currently characterized by an efficiency slightly greater than $50 \%$ for two-stroke engines, and just under $50 \%$ for four-stroke ones. An efficiency increase of the on-board systems using such engines can be obtained by the partial recovery of their waste heat, by means of a Heat Recovery Steam Generator (HRSG), able to feed a steam turbine generally for electric energy production, in order to reduce the on-board diesel-generator's power. To this purpose, different schemes of Waste Heat Recovery (WHR) steam plants, applied to marine diesel engines, are proposed in the literature [7-18], characterized by singleor dual-pressure steam plants. 
The energy conversion efficiency increase obtained by these plants, compared to installations without WHR, varies between approximately 3 and 5\%. This last value can generally be obtained by adopting, in addition to the WHR steam plant, a gas turbine powered by a part of the exhaust gas coming from the engine cylinders. This is possible thanks to the current high efficiency of the turbochargers used for marine applications. Indeed, to supply sufficient air to the engine cylinders, it is not necessary to send all the exhaust gas to the turbocharger turbine, but a portion (generally about $10 \%$ ) can be sent to another turbine (power gas turbine), running in parallel to the turbocharger turbine, for electricity production $[12,18]$. Another way to increase the efficiency of WHR systems is to adequately exploit (by means of heat exchangers) the heat of the air at the turbocharger compressor outlet, as described in [19].

As regards the type of fuel, the use of natural gas (NG) instead of the more traditional Heavy Fuel Oil (D) strongly reduces engine polluting emissions (indicatively [20]: carbon dioxide $-25 \div-30 \%$, carbon monoxide: $-25 \%$, nitrogen oxides $-85 \%$, sulphur oxides $-99 \div-100 \%$, particulate matter $-90 \div-99 \%$ ). Furthermore, at medium-high engine loads [20], the NG allows $1 \div 2 \%$ higher engine efficiency compared to traditional marine liquid fuels.

Similarly, in the case of liquid fuel diesel engines, and for natural gas (NG) or dual-fuel (DF) engines, it is possible to increase the efficiency of the on-board systems by adopting WHR steam plants, with or without $[21,22]$ power gas turbine, for electric energy production. In this way the energy conversion efficiency increases by about the same percentages mentioned before.

In order to reduce marine engine fuel consumption and cut carbon dioxide emissions, since 2007 the Mitsubishi Heavy Industries has published several works [23-27] regarding the development of a hybrid turbocharger with an integrated high-speed electric motor-generator, to be used in marine diesel engines as a substitution for the traditional turbocharger. An application of the hybrid turbocharger to a two stroke diesel engine of a bulk carrier is reported in [28].

In this paper, a simulation model of a hybrid turbocharger is presented as an integration of an already developed and validated simulator of a dual-fuel four-stroke marine engine [29]. The model is applied to simulate the behaviour of the engine, running with NG fuel, when the original turbocharger is replaced by the hybrid one. In the development of the calculations it is considered that the original compressor and turbine performance maps are maintained for the hybrid turbocharger. The analysis carried out makes it possible to compare the performance of the engine running both with the original turbocharger and with the hybrid turbocharger. The results obtained, presented in tabular and graphical form, refer to the engine running in steady-state conditions for different engine loads and speeds.

\section{Hybrid Turbocharger}

In recent years the increased efficiency of the turbochargers used in particular on diesel and DF marine engines of medium-high powers has often determined an excess of turbine torque compared to that required by the compressor. To solve this problem a common practice is to divert a portion of the cylinders exhaust gas (indicatively 10\% [24] when the engine is working in Normal Continuous Rating (NCR) condition) from the exhaust manifold to reduce the turbocharger (TC) turbine mass flow, in order to balance its torque to that of the TC compressor.

Obviously, this solution is at the expense of overall efficiency, unless this part of the exhaust gas is sent to a second turbine to produce power (power gas turbine), as mentioned above. Another very interesting solution is that proposed a few years ago and subsequently developed by Mitsubishi Heavy Industries [23]. This company has developed, for marine applications, a hybrid turbocharger (HTC) with integrated a high-speed electric motor-generator, installed in the TC silencer as shown in Figure 1. 


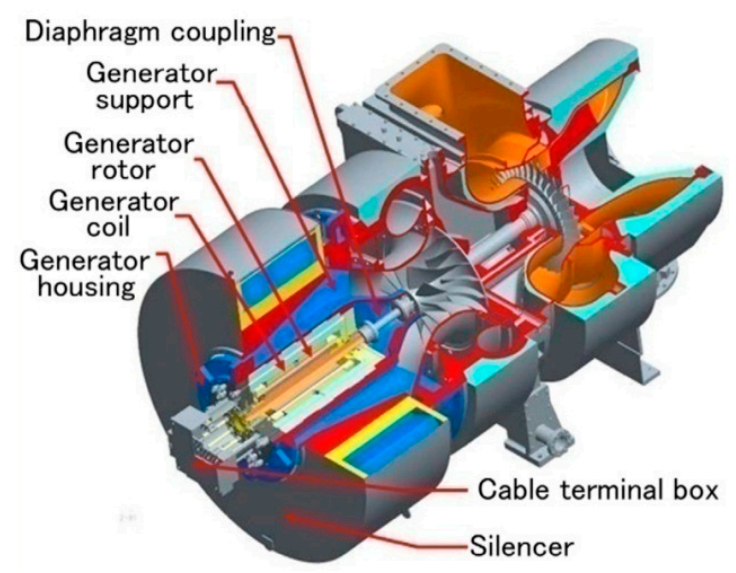

Figure 1. Cross-sectional view and main Electric Motor-Generator (EM-G) components of the hybrid turbocharger [25].

The HTC uses a portion of the turbine torque (originated from the exhaust gas energy) to drive an electric generator, thereby acting as a particular type of waste heat recovery system. As reported in [24] the HTC electric generator can be used also as electric motor, to increase the engine TC speed, hence the name used here of Electric Motor-Generator (EM-G). This last option is not considered in this work.

The main characteristics of the Mitsubishi EM-G and the results of operative tests are reported in several papers [23-27]. Currently a prototype of an HTC is used in the $20.09 \mathrm{~kW}$ MAN 7S65ME-C two-stroke propulsion engine of a bulk carrier $[25,28]$.

The maximum electric output power of the EM-G is $1300 \mathrm{~kW}$ [24], with the possibility to control the electric power generated by the HTC, as well as the electric voltage and frequency [25], by means of an inverter, as discussed more in detail below. From the above considerations, it seems, therefore, that there is a real possibility of using the hybrid turbocharger to generate electricity able to satisfy part of the electric load of the ship, easing the task of diesel generators.

In order to explore this possibility in detail and to quantify the potential advantages of applying the hybrid turbocharger to different types of marine engines, in this study the authors propose to "generate", by simulation, an HTC in which the TC compressor and turbine characteristics are those of the MAN 51/60 DF 12V four-stroke dual-fuel marine engine, but the original turbocharger is modified with the introduction of the aforementioned Mitsubishi EM-G. As discussed below, the use of the hybrid turbocharger involves a radical change of the current regulation logic of the power supplied by the engine, increasing its overall efficiency thanks to the increased electrical power generated at the same fuel consumption.

After having briefly explained the operating principle of the hybrid turbocharger from an energetic point of view, and having identified in the simulation a useful approach to evaluate the advantages of this innovative technology in marine systems, it is very important now to consider and face the electrical problems connected to the realization of the hybrid turbocharger.

Electric machines are more and more applied not only for power generation, but also for main propulsion and auxiliary propellers.

The use of a hybrid turbocharger poses significant challenges to properly design an efficient electric machine since there is a strong necessity to use a very compact and high-speed machine $(12,000 \mathrm{rpm})$. The actual solution to overcome these issues is the adoption of permanent magnet 3-phase alternating current (AC) synchronous generator that allows significant performance. Since three phase power output from the generator depends upon the speed of the turbocharger, the alternator cannot be connected directly to shipboard electric network.

Therefore, it is necessary to provide an intermediate conversion through a direct current (DC) rectifier, before converting the $\mathrm{AC}$ power to the appropriate voltage and frequency for shipboard 
network. The main solution is nowadays the application of IGBT (Insulated Gate Bipolar Transistor) technology for active rectification, as well as an inverter as depicted in Figure 2. In fact, modern power electronics allows a very precise control of the electric machines. A Voltage Source Inverter (VSI) with an Active Front End (AFE) is shown in Figure 2, highlighting the detailed setup and the different control loops for the correct modulation of the bridge using PWM (pulse-width modulation) technique.

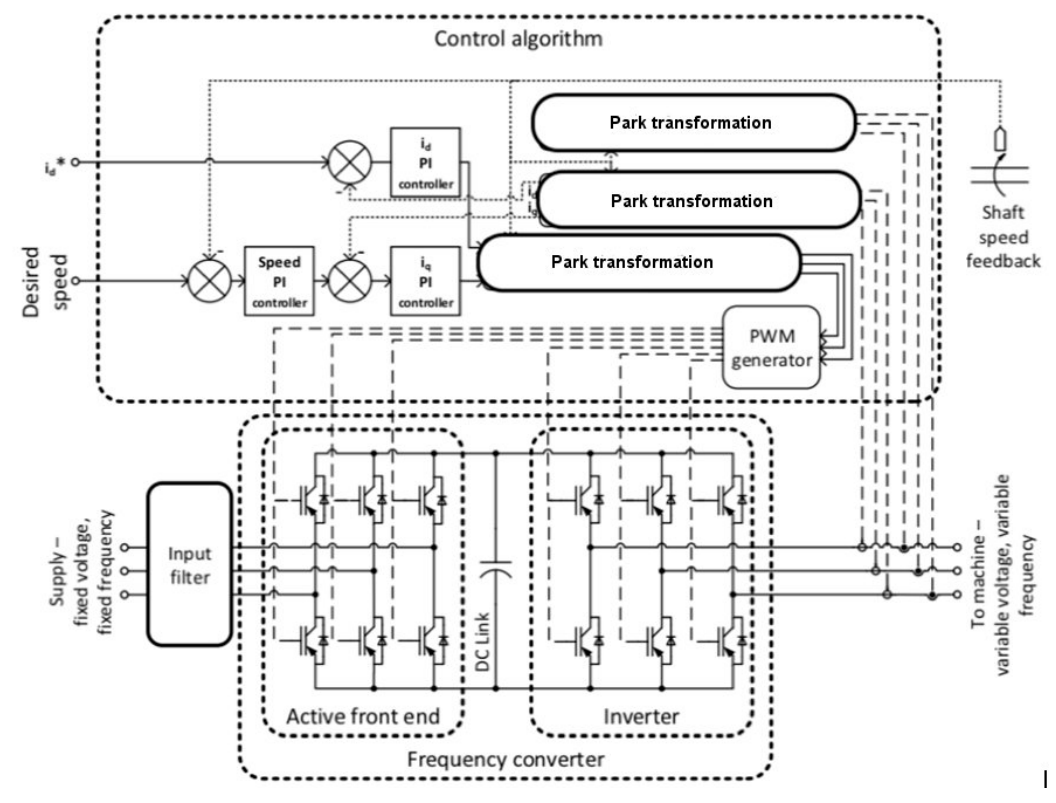

Figure 2. VSI with a Active Front End layout and relative control loops.

With an AFE power can be controlled, such that current waveforms can be modulated to control also the power factor absorbed from the network. Most importantly for the purpose of auxiliary drivers, it permits reverse power flow, different from the traditional diode bridge rectifier, even if cost is significantly increased. This is extremely important since it allows to use the EM-G as motor to accelerate the turbocharger rotor and control it in a very precise and fast way with respect to the mechanical dynamics [30].

\section{Engine Simulator}

As mentioned above, this study is focused on the MAN 51/60 DF 12V, a four-stroke dual-fuel marine engine, characterized by $12 \mathrm{MW}$ of Maximum Continuous Rating (MCR) power at $514 \mathrm{rpm}$. Table 1 shows the main engine technical data, provided by the manufacturer [31].

Table 1. MAN 51/60 DF 12V engine main dimensions and design (MCR) data.

\begin{tabular}{cc}
\hline Engine Parameters & D/NG \\
\hline Engine length $(\mathrm{mm})$ & 10,254 \\
Height $(\mathrm{mm})$ & 5517 \\
Width $(\mathrm{mm})$ & 4713 \\
Dry weight $(\mathrm{t})$ & 189 \\
cylinders number $(\mathrm{V})$ & 12 \\
bore $(\mathrm{mm})$ & 510 \\
stroke $(\mathrm{mm})$ & 600 \\
brake power $(\mathrm{kW})$ & 12,000 \\
speed $(\mathrm{rpm})$ & 514 \\
(b.m.e.p.) $(\mathrm{bar})$ & 19.1 \\
BSFC [g/kWh] & $189 / 157$ \\
charge air pressure (bar $\left.\mathrm{g}_{\mathrm{g}}\right)$ & $4.29 / 3.77$ \\
\hline
\end{tabular}


As discussed in the introduction of the paper, a full thermodynamic simulation model of this engine, developed in Matlab ${ }^{\circledR}$-Simulink ${ }^{\circledR}$ language, has been already presented in a previous authors' article [29]. Figure 3 shows the complete dual-fuel engine simulator scheme, organized in modular form, already inclusive of the HTC EM-G module ("electric motor-generator" block in Figure 3).

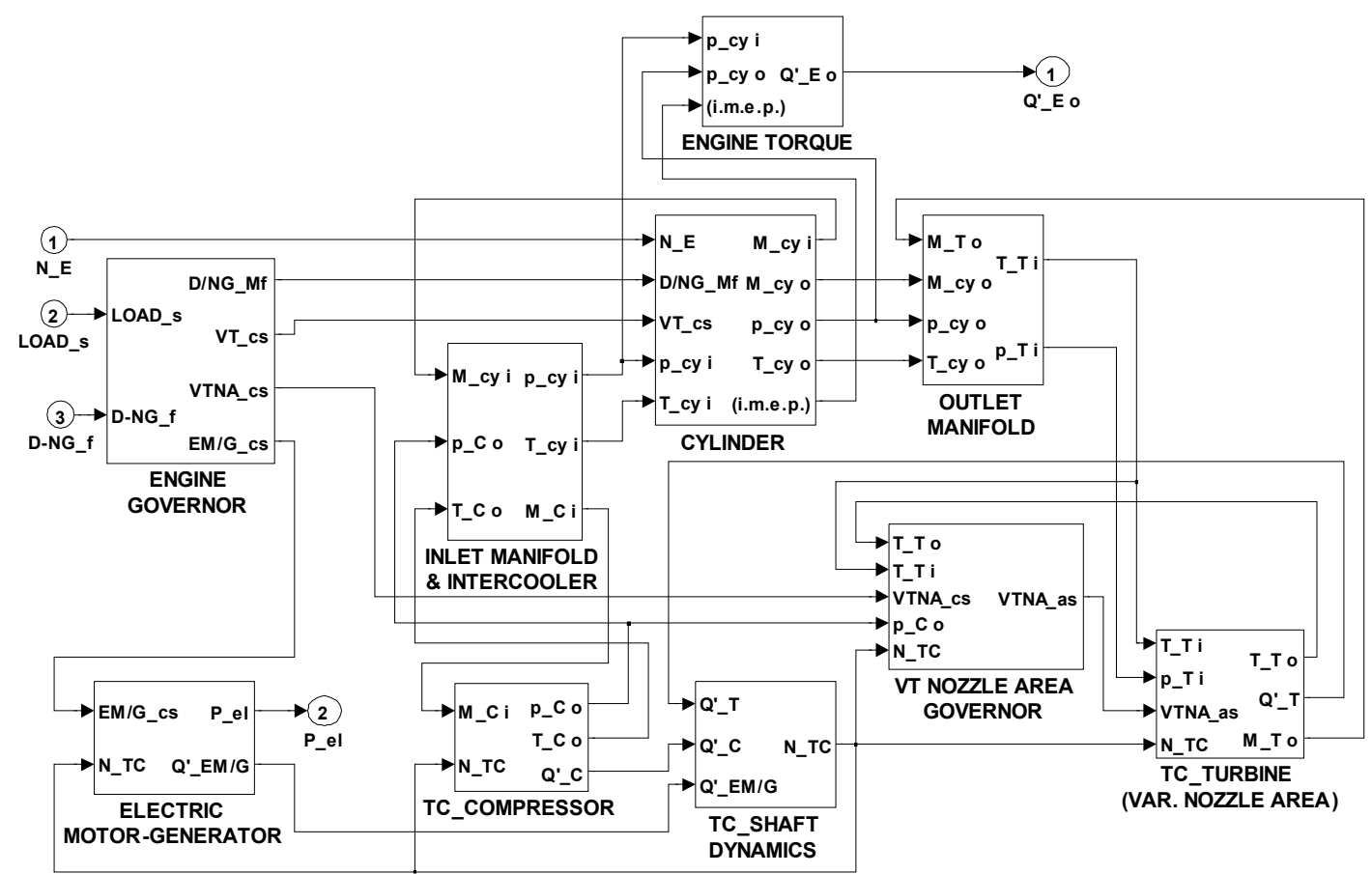

Figure 3. SIMULINK scheme of the MAN 51/60 DF 12V engine simulator (with hybrid turbocharger).

Each module of the model simulates the performance and characteristics of the pertinent engine component by means of algebraic and differential equations, and/or steady-state performance maps, using a filling and emptying simulation approach [29].

In particular, the cylinder module reproduces the in-cylinder phenomena by means of thermodynamics calculations that proceed step-by-step with the crank angle variation. The engine can operate in the Miller cycle mode, because it is equipped with variable valve timing of the intake valve opening and closing. The intake valve setting varies with engine load and fuel type as reported in detail in Reference [29]. The turbocharger simulation is based on the use of the typical steady-state performance maps for compressor and turbine, combined with the numerical solution of the turbocharger shaft dynamic equation (TC_shaft dynamics block in Figure 3). The electric motor-generator module, added specifically for this research to the model of Figure 3, receives as input, from the engine governor block, a signal representing the required electric power and, from the TC_ shaft dynamics, the turbocharger speed. The output signals of the electric motor-generator block are the electric power delivered and the EM-G torque.

The engine simulator has been fully validated for different steady-state working conditions (between 100\% and 25\% of the engine MCR), both at constant and variable speed [29]. A good agreement between the results of the simulator and the reference data (supplied by the manufacturer) can be observed for all the variables considered in the validation, for the engine operating both in diesel mode and in natural gas mode. The errors between calculated and reference values generally remain less than $2 \%$ at high engine loads ( $85-100 \%$ MCR), while for a few variables they are less than $4 \%$ at medium-low engine loads. 


\section{Hybrid Turbocharger Implementation}

Figure 4 shows the functional scheme of the DF marine engine chosen for the simulation. The scheme for the original turbocharger is replaced, as anticipated above, by a hybrid turbocharger, characterized, as shown in the figure, by the presence of additional components (EM-G and inverter). The electric energy produced by the EM-G, once converted into the required voltage and frequency by the inverter, is sent to the on-board electrical system, in parallel with the energy produced by diesel generators (DG).

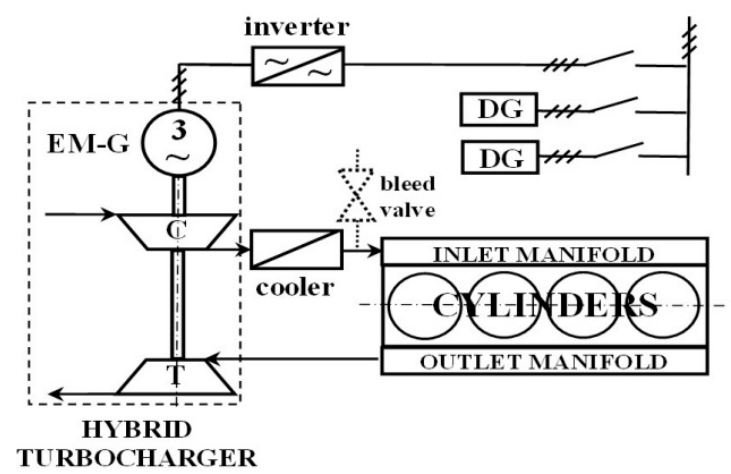

Figure 4. Scheme of the proposed engine with hybrid turbocharger.

The TC turbine is characterized by a variable nozzle area (VTNA), as visualized in the engine SIMULINK scheme of Figure 3. As reported in greater detail in [29], the engine load control is different depending on the type of fuel used. In the case of diesel fuel, the classical approach of graduating the fuel mass injected in the cylinders is adopted, and the 'bleed valve' (see Figure 4) is partially open according to a logic dependent on engine speed and fuel mass injected in the cylinders.

When NG fuel is used with the originally adopted turbocharger, the torque delivered by the engine is governed by the aforementioned 'bleed valve'. It is known that in this case the cylinders are working with approximately constant equivalence ratio $(\Phi)[29]$. As the 'bleed valve' opening increases, the turbocharger speed decreases and also the inlet manifold pressure decreases. As a consequence, less air mass flow is introduced in the cylinders, causing an engine delivered torque decrease. The TC turbine torque is also governed (in the case of NG fuel only) by the TC turbine VTNA, with a logic described in Reference [29]. The air discharged in the ambient through the 'bleed valve' (see Figure 4), constitutes an energy loss of the engine, because this air is previously compressed by TC compressor.

When NG fuel is used, an interesting alternative way to control the speed of the turbocharger and consequently the load of the engine, is represented by the use of the hybrid turbocharger described in the present study, according to the scheme shown in Figure 4. In this case, the 'bleed valve' remains closed. The TC speed is then governed by the hybrid turbocharger through the control of the electric motor-generator ('EM-G' in Figure 4), by varying the electric energy produced by this component. Indeed, the TC speed depends by the shaft torque dynamic equation:

$$
\frac{d \omega}{d t}=\frac{1}{J}\left(Q_{\mathrm{T}}^{\prime}-Q_{\mathrm{C}}^{\prime}-Q_{\mathrm{EM}-\mathrm{G}}^{\prime}\right)
$$

Equation (1) shows that the TC speed can be varied by governing the EM-G torque $\left(Q^{\prime}\right.$ EM-G). By controlling the speed of the turbocharger, it is possible to govern the load of the engine. Moreover, it is possible to have available electric power which, by means of an inverter, can be made compatible, in terms of frequency and voltage, with the on-board electrical system. This electricity can then be used to satisfy part of the ship's electric power load, as shown in Figure 4. 
After the introduction of the hybrid turbocharger replacing the original one, the SIMULINK simulation model of the engine assumes the configuration already shown in Figure 3.

As regards the challenging problem of engine management, Figure 5 shows a possible overall scheme for the control of the DF engine with hybrid turbocharger, which is able to govern the engine load in all possible working conditions: diesel or NG fuel, constant or variable engine speed, and so on.

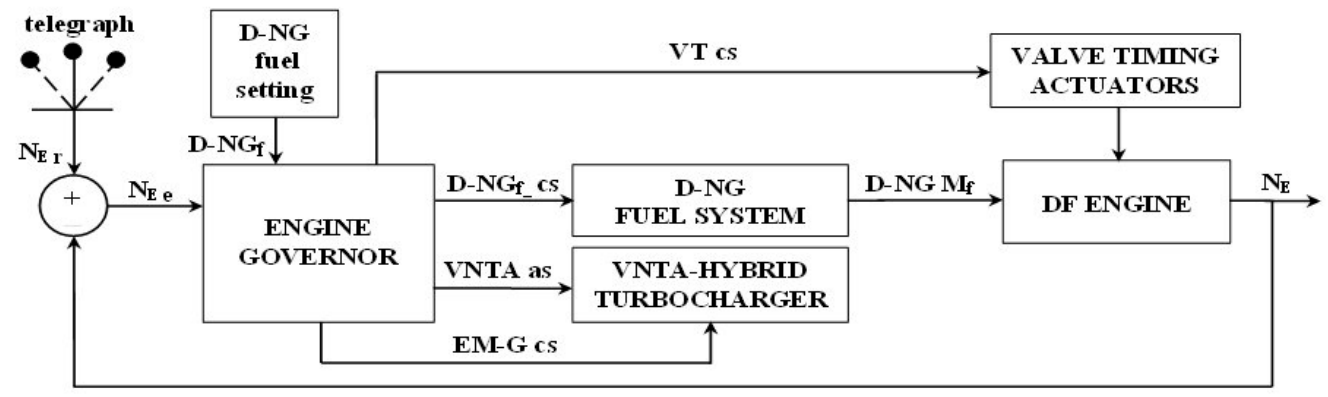

Figure 5. Overall control scheme of the DF engine with hybrid turbocharger.

Due to the complexity of the overall engine control system, only the main functions are summarized here. With reference to the scheme of Figure 5, once the required engine load is defined with the 'telegraph', and the selected fuel type (diesel or NG) with the 'D-NG fuel setting' block, there are two possibilities depending on the type of fuel. In the case of diesel fuel the 'ENGINE GOVERNOR' block manages the pertinent fuel system (through the 'D-NG FUEL SYSTEM' block) and the timing for opening or closing the cylinder valves (through the 'VALVE TIMING ACTUATORS' block). In this case, the TC turbine VTNA remains always fully open, and the hybrid turbocharger EM-G is disabled.

When the fuel selected is natural gas, the 'ENGINE GOVERNOR' block manages the pertinent fuel system and the cylinders valves timing. In this case, the TC turbine VTNA and the hybrid turbocharger EM-G are also activated ('VNTA-HYBRID TURBOCHARGER' block in Figure 5). In this situation, only the electric generator operation mode is used to obtain the required engine speed, as shown in Figure 4. Indeed, to control the engine load when NG fuel is used, a variation in the original engine control system logic is introduced, regarding the use of the hybrid TC EM-G, in place of the 'bleed valve'. The engine governor setting does not change with respect to the original [29] for the other engine components (e.g., valve timing actuators control). Since the dynamics of the Voltage Source Inverter (VSI) is significantly faster than the mechanical processes involved, in the simulation model the electrical operations and their control have been assumed as instantaneous, taking into consideration only generation and commutation losses.

\section{Turbochargers Comparison}

The new hybrid turbocharger solution, compared with the originally adopted one, is here proposed, as already mentioned, for the dual-fuel marine engine working in natural gas mode. A similar comparison for the same engine, running on diesel fuel, requires a more complex study, due to the greater number of variables to consider to optimize each engine working point.

The results obtained by the simulation, shown in Tables 2 and 3, are relative to the engine working in constant (Table 2) and variable speed (Table 3), for different engine loads: $100 \%, 85 \%, 75 \%, 50 \%$ and $25 \%$ of the MCR power. 
Table 2. Conventional and hybrid turbocharger comparison for different engine working points and constant speed (514 rpm).

\begin{tabular}{ccccccc}
\hline Line & Engine Parameters & \multicolumn{5}{c}{ Engine Loads } \\
\hline 1 & Engine power $(\%$ of MCR) & 100 & 85 & 75 & 50 & 25 \\
2 & Engine power $(\mathrm{kW})$ & 12,000 & 10,260 & 9000 & 6000 & 3000 \\
3 & EM/G electric power $(\mathrm{kW})$ & 531 & 600 & 716 & 600 & 374 \\
4 & EM/G el. pow. $(\%$ of E pow.) & 4.42 & 5.85 & 7.95 & 10.00 & 12.47 \\
5 & $\mathrm{~N}_{\mathrm{TC}}(\Delta \%)$ & -6.31 & -7.96 & -11.78 & -22.01 & -49.65 \\
6 & $\beta_{\mathrm{C}}(\Delta \%)$ & -9.57 & -9.09 & -15.18 & -18.75 & -25.46 \\
7 & Compressor $\mathrm{e}$ temp. $(\Delta \%)$ & -3.84 & -4.22 & -5.46 & -6.52 & -6.89 \\
8 & Compr. M air $(\Delta \%)$ & -6.32 & -10.04 & -10.70 & -9.45 & -7.31 \\
9 & Compr. efficiency $(\Delta \%)$ & -0.12 & 0.65 & 1.60 & 0.97 & 1.06 \\
10 & $\mathcal{E}_{\mathrm{T}}(\Delta \%)$ & 0.22 & 1.17 & 0.58 & 2.62 & 8.42 \\
11 & Turbine ${ }_{\mathrm{i}}$ pressure $(\Delta \%)$ & 0.21 & 0.39 & 0.61 & 0.25 & 0.32 \\
12 & Turbine $\mathrm{i}_{\mathrm{i}}$ temp. $(\Delta \%)$ & -0.12 & -0.17 & -0.34 & -0.21 & -0.58 \\
13 & Turbine efficiency $(\Delta \%)$ & 0.00 & 0.01 & 0.01 & -0.01 & 0.01 \\
14 & Cylinder inlet air mass $(\Delta \%)$ & 0.01 & -0.01 & 0.01 & 0.01 & 0.01 \\
15 & Cylinder inlet air temp. $(\Delta \%)$ & -0.51 & -0.68 & -0.61 & -0.29 & -0.79 \\
16 & Cylinder exh. gas mass $(\Delta \%)$ & 0.01 & 0.02 & 0.01 & 0.02 & 0.02 \\
17 & Engine IMEP $(\Delta \%)$ & -0.02 & -0.02 & -0.03 & -0.01 & -0.02 \\
18 & Orig. TC engine eff. $\left(\Delta \eta_{\mathrm{E}} \%\right)$ & -0.01 & -0.01 & 0.01 & -0.01 & 0.02 \\
19 & HTC engine eff. $\left(\Delta \eta_{\mathrm{E}} \mathrm{HTC} \%\right)$ & 2.10 & 4.20 & 3.72 & 2.90 & 2.81 \\
\hline
\end{tabular}

With reference to Table 2, the data reported in the Line 3 show the electric energy amount produced by the HTC, and in Line 4 the percentage of this electric power with respect to the engine mechanical delivered power (reported on Line 2 of the table). The data presented in Lines 3 and 4 show the substantial power recovered by the hybrid TC.

The results reported in Table 2 from Line 5 to Line 19 show the comparison between the original and the hybrid turbocharger, expressed as the percentage differences between the engine parameters, calculated according to the formula:

$$
\Delta x \%=\frac{x_{\mathrm{HYTC}}-x_{\mathrm{orTC}}}{\eta_{\mathrm{orTC}}} \times 100
$$

where $x$ is the considered parameter.

The results reported in Table 2 from Line 5 to Line 13, all pertinent to the turbocharger, show that the adoption of the hybrid turbocharger involves a considerable variation in the operating conditions of this engine component. This is confirmed by the working points reported in the compressor map visualized in Figure 6a, for the original TC, and in Figure $6 \mathrm{~b}$ for the hybrid TC.

From the results shown in Figure 6 and those reported in Table 2, it can be observed that, at the same engine load and rotational speed, the hybrid TC works at lower speed, compression ratio and volumetric mass flow, when compared to the original one. This occurs for the engine operating at both constant and variable speed. Nevertheless, the engine cylinders work in about the same conditions for the same engine load, as reported in Table 2 from Line 14 to Line 16. This is also confirmed by the engine indicate mean effective pressure (IMEP in Line 17 of Table 2) and by the engine efficiency $\left(\eta_{\mathrm{E}} \%\right)$, as shown in Line 18 of the same table. This efficiency, expressed by:

$$
\eta_{\mathrm{E}} \%=\frac{P_{\mathrm{E}}}{M_{\mathrm{f}} \mathrm{FLHV}} \times 100
$$

does not consider the electric energy produced by the HTC. 
The HTC electric power, in addition to the mechanical engine power, leads to a substantial increase of the overall engine efficiency $\left(\eta_{\mathrm{E}} \mathrm{HTC}\right)$, determined by the equation:

$$
\eta_{\mathrm{EHTC}} \%=\frac{P_{\mathrm{E}}+P_{\mathrm{elEMG}}}{M_{\mathrm{f}} \mathrm{FLHV}} \times 100
$$

as reported in Line 19 of Table 2 and in Line 20 of Table 3.

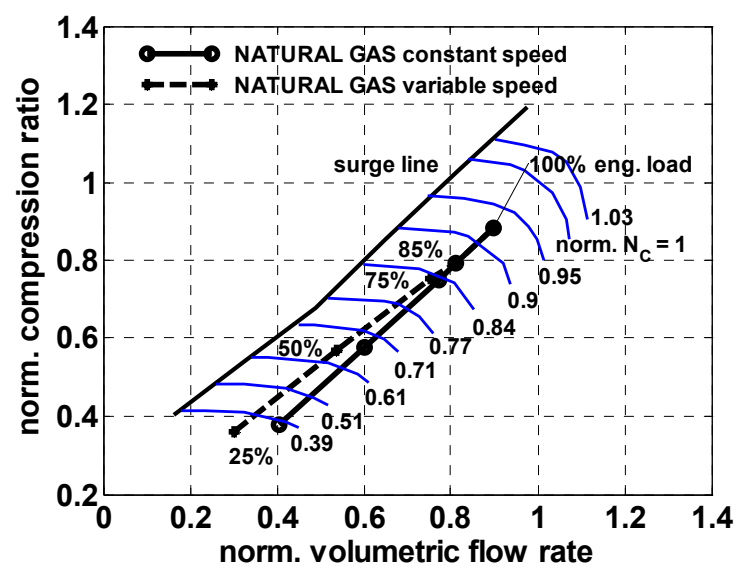

(a)

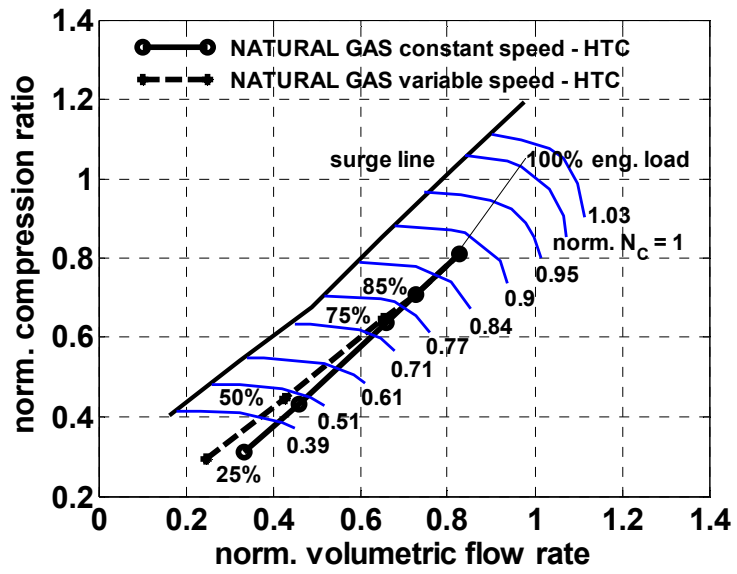

(b)

Figure 6. Compressor maps of the NG engine with original (a) turbocharger and hybrid (b) turbocharger: calculated working points for different engine loads, at both constant and variable engine speed.

The same considerations made above about the data reported in Table 2 can also be repeated for Table 3, concerning the engine operating at variable speed.

Table 3. Conventional and hybrid turbocharger comparison for different engine working points and variable speed.

\begin{tabular}{|c|c|c|c|c|c|c|}
\hline \multirow{2}{*}{$\begin{array}{c}\text { Line } \\
1\end{array}$} & \multirow{2}{*}{$\begin{array}{c}\text { Engine Parameters } \\
\text { Engine power (\% of MCR) }\end{array}$} & \multicolumn{5}{|c|}{ Engine Loads } \\
\hline & & 100 & 85 & 75 & 50 & 25 \\
\hline 2 & Engine power $(\mathrm{kW})$ & 12,000 & 10,260 & 9000 & 6000 & 3000 \\
\hline 3 & Engine speed (rpm) & 514 & 514 & 501 & 462 & 402 \\
\hline 4 & EM/G electric power $(\mathrm{kW})$ & 490 & 542 & 562 & 567 & 241 \\
\hline 5 & EM/G el. pow. (\% of E pow.) & 4.08 & 5.28 & 6.24 & 9.45 & 8.03 \\
\hline 6 & $\mathrm{~N}_{\mathrm{TC}}(\Delta \%)$ & -6.74 & -8.00 & -10.64 & -17.55 & -38.94 \\
\hline 7 & $\beta_{C}(\Delta \%)$ & -9.57 & -6.67 & -15.63 & -19.91 & -27.03 \\
\hline 8 & Compressor $_{\mathrm{e}}$ temp. $(\Delta \%)$ & -3.85 & -4.44 & -5.67 & -5.52 & -6.76 \\
\hline 9 & Compr. $\mathrm{M}$ air $(\Delta \%)$ & -8.92 & -10.42 & -13.06 & -15.69 & -18.47 \\
\hline 10 & Compr. efficiency $(\Delta \%)$ & 0.12 & 1.60 & 1.71 & 1.29 & 2.02 \\
\hline 11 & $\varepsilon_{\mathrm{T}}(\Delta \%)$ & 0.21 & 1.18 & 0.58 & 2.43 & 3.29 \\
\hline 12 & Turbine $_{i}$ pressure $(\Delta \%)$ & 0.22 & 0.16 & 0.53 & 0.34 & 0.27 \\
\hline 13 & Turbine $_{\mathrm{i}}$ temp. $(\Delta \%)$ & -0.14 & -0.16 & -0.39 & -0.26 & -0.45 \\
\hline 14 & Turbine efficiency $(\Delta \%)$ & 0.00 & -0.01 & 0.00 & 0.01 & 0.01 \\
\hline 15 & Cylinder inlet air mass $(\Delta \%)$ & 0.01 & 0.02 & 0.01 & -0.01 & 0.01 \\
\hline 16 & Cylinder air temp. $(\Delta \%)$ & -0.55 & -0.63 & -0.59 & -0.43 & -0.66 \\
\hline 17 & Cylinder exh. gas mass $(\Delta \%)$ & 0.01 & -0.01 & 0.01 & -0.01 & 0.02 \\
\hline 18 & Engine IMEP $(\Delta \%)$ & -0.01 & -0.03 & -0.01 & -0.02 & -0.02 \\
\hline 19 & Orig. TC engine eff. $\left(\Delta \eta_{E} \%\right)$ & -0.01 & -0.02 & 0.01 & -0.01 & 0.02 \\
\hline 20 & HTC engine eff. $\left(\Delta \eta_{\mathrm{E}} \mathrm{HTC} \%\right)$ & 1.93 & 3.71 & 2.79 & 2.68 & 1.93 \\
\hline
\end{tabular}


The comparison of the two turbochargers, carried out by means of a simulation model developed for the purpose, allows us to highlight some advantages of the hybrid turbocharger compared with the original one. The original turbocharger is in fact characterized by a loss of energy due to the air discharged into the ambient through the bleed valve (see Figure 4), used in the current configuration of the engine for the load control. The hybrid turbocharger, instead, manages the engine load by varying the electrical energy produced by the electric machine, driven by the excess torque of the turbine, thus varying the speed of the turbocharger, but keeping the thermodynamic cycle unchanged in the cylinders.

Figure 7 shows the engine efficiency increase due to the hybrid turbocharger electric power production, for different engine loads and constant or variable engine speed.

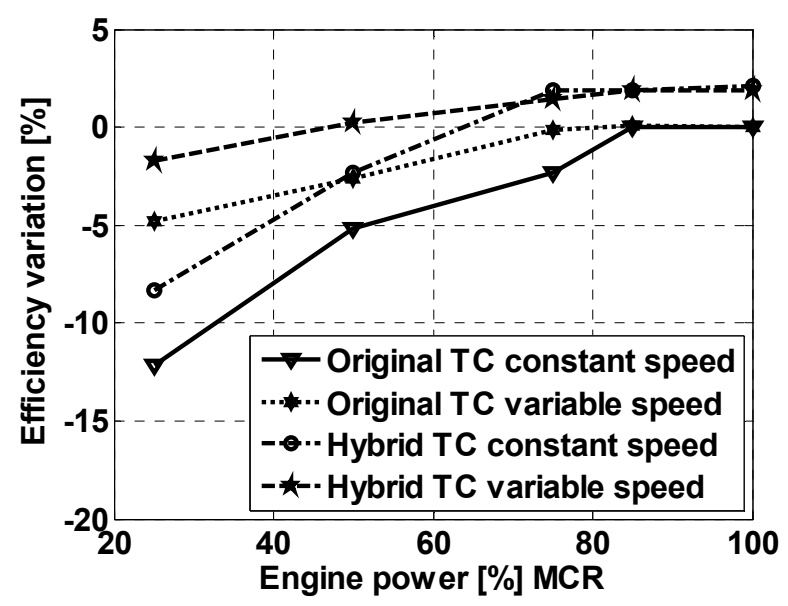

Figure 7. Original and hybrid turbocharger comparison in terms of engine efficiency for different engine loads and constant or variable engine speed.

An efficiency increase of about $2.3 \%$ can be observed from the figure, at high engine load (100-85\% MCR power), with engine running both at constant and variable speed. When the engine power is equal or lower than $75 \% \mathrm{MCR}$, the difference in engine efficiency for the hybrid turbocharger solution increases further compared to the conventional turbocharger solution. In particular, the efficiency difference becomes very consistent at $75 \%$ engine load in constant-speed working conditions. This is due to the high efficiency of the turbocharger components (compressor and turbine) in this engine working point, which facilitates high electric power generation, as reported in Line 4 of Table 2.

\section{Conclusions}

This paper presents a simulation analysis of the performance of an existing dual-fuel four-stroke marine engine, equipped with two different turbochargers. The first is the currently used turbocharger, the second is a new hybrid turbocharger, the rotor shaft of which moves, in addition to the compressor, a generator for the production of electricity. This electric generator is also used to control the speed of the turbocharger and consequently the torque delivered by the engine. From this point of view the hybrid turbocharger is advantageous compared to the original one, which, to regulate the speed of the turbocharger, discharges a percentage of air into the ambient through the bleed valve, causing a loss of energy and altering the thermodynamic parameters of the engine. However, the main advantage of the hybrid turbocharger adoption is in the non-negligible production of electric power, ranging from $4.1 \%$ to $12.4 \%$ of the engine power when the engine decreases from $100 \%$ to $25 \%$ (see Tables 2 and 3) This power can be used to satisfy part of the ship's electric power demand, reducing the use of diesel generators, with a consequent reduction of fuel consumption and polluting emissions, in particular carbon dioxide emissions. In this paper the comparison of the two turbochargers, carried out by means of a simulation model developed for the purpose, allows us to quantify the advantages 
of the hybrid turbocharger compared with the original one in a large range of engine power and speed, as reported in detail.

The results obtained demonstrate the validity of the hybrid turbocharger solution in marine applications, and the opportunity to work to make this solution an industrially mature product.

A possible extension of the present research, which the authors intend to develop in the near future, concerns a comparison between the hybrid and the conventional turbocharger for the same dual-fuel marine engine running on diesel fuel.

Author Contributions: Although the tasks entrusted to the individual participants have been appropriately differentiated (bibliographic research, development and validation of computational codes, comparison of results, writing of the article, subsequent revisions of it, etc.), it can be stated the substantial equivalence of the contribution that each author has provided, in quantitative and qualitative terms, for the preparation of this article.

Funding: This research received no external funding.

Acknowledgments: The authors are grateful to MAN Diesel and Turbo and engineer Andrea Rossetto of Ranieri Tonissi S.p.A. Genova for their precious cooperation.

Conflicts of Interest: The authors declare no conflicts of interest.

\section{Nomenclature}

As

BSFC

b.m.e.p.

CC

CS

D

DG

D-NG

E

EM-G

FLHV

HTC

J

IMEP

$\mathrm{M}$

MCR

$\mathrm{N}$

NG

$p$

$P$

$Q^{\prime}$

$\mathrm{T}$

TC

VSI

VT

VTNA

$\beta$

$\Delta$

$\varepsilon$

$\eta$

$\Phi$ actuator signal

brake specific fuel consumption

brake mean effective pressure

engine-TC electric motor/generator combined cycle

control signal

heavy fuel oil

diesel-generator

diesel-natural gas

engine

turbocharger electric motor-generator

fuel lower heating value

hybrid turbocharger

rotor inertia

gross indicated mean effective pressure

mass flow rate

engine maximum continuous rating

rotational speed

natural gas

pressure

power

shaft torque

turbine, temperature

turbocharger

Voltage Source Inverter

engine valve timing

variable turbine nozzle area

turbocharger compressor pressure ratio

difference

turbocharger turbine expansion pressure ratio

efficiency

equivalence ratio 


$\begin{array}{ll}\text { Subscripts } & \\ \text { as } & \text { actuator signal } \\ \text { C } & \text { compressor } \\ \text { cs } & \text { control signal } \\ \text { E } & \text { engine } \\ \text { EM-G } & \text { electric motor-generator } \\ \text { e } & \text { error } \\ \text { el } & \text { electric } \\ \text { ex gas } & \text { exhaust gas } \\ \text { f } & \text { fuel } \\ \text { HTC, HY } & \text { hybrid turbocharger } \\ \text { i } & \text { inlet } \\ \text { Mf } & \text { fuel mass flow rate } \\ \text { o } & \text { outlet } \\ \text { or } & \text { original turbocharger } \\ \text { r } & \text { required } \\ \text { T } & \text { turbine, temperature } \\ \text { TC } & \text { turbocharger }\end{array}$

\section{References}

1. International Maritime Organization (IMO). Resolution A. 963 (23). IMO Policies and Practices Related to the Reduction of Greenhouse Gas Emissions from Ships. Available online: http: / rise.odessa.ua/texts / A96 3_23e.php3 (accessed on 17 July 2018).

2. International Maritime Organization (IMO). Marine Environment Protection Committee (MEPC). Available online: http:/ / www.imo.org/en/KnowledgeCentre/IndexofIMOResolutions/Marine-Environment-Prot ection-Committee- (accessed on 17 July 2018).

3. Marine Environment Protection Committee (MEPC). Resolution, MECP 212 (63/23), Annex 8. 2012. Guidelines to the Method of Calculation of the Attained Energy Efficiency Design Index (EEDI) for New Ships. Available online: http:/ / www.imo.org/en/OurWork/Environment/PollutionPrevention/AirPoll ution/Documents/212\%2863\%29.pdf (accessed on 17 July 2018).

4. Marine Environment Protection Committee (MEPC). In Proceedings of the International Maritime Organization (IMO), 66th session, London, UK, 31 March-4 April 2014. Available online: http:/ / www.imo.org/en/KnowledgeCentre/IndexofIMOResolutions/Marine-Environment-Protec tion-Committee-(MEPC)/Pages/default.aspx (accessed on 23 July 2018).

5. International Maritime Organization (IMO). Energy Efficiency Ship Operation. Module 2-Ship Energy Efficiency Regulation and Related Guidelines; IMO: London, UK, January 2016.

6. Gualeni, P.; Boveri, A.; Silvestro, F.; Margarita, A. Decision Support System for Power generation Management for 110,000-GRT Cruise Ship. Int. J. Marit. Eng. 2016, 158, 163-175. [CrossRef]

7. Ioannidis, J. Waste Heat recovery from Diesel Engines. In Proceedings of the IMAM 1984 Conference, Athens, Greece; 1984. Available online: http:/ / www.lme.ntua.gr:8080/academic-info-1/prospheromena-mathemata / egkatastaseis-prooses/files/waste_heat_from_diesel_engines.pdf (accessed on 17 July 2018).

8. Ioannidis, J. Thermo Efficiency System (TES) for Reduction of Fuel Consumption and CO2 Emission; Aalborg A. G.: Copenhagen, Denmark, 1984.

9. Schmidt, H. Less Emissions through Waste Heat Recovery. In Proceedings of the Presented at the Green Ship Technology Conference, London, UK, 28-29 April 2004.

10. Ito, K.; Akagi, S. An Optimal Planning Method for a Marine Heat and Power Generation Plant by Considering its Operational Problem. Energy Res. 1986, 10, 75-85. [CrossRef]

11. Tien, W.K.; Yeh, R.H.; Hong, J.M. Theoretical Analysis of Cogeneration System for Ships. Energy Convers. Manag. 2007, 48, 1965-1974. [CrossRef]

12. Dzida, M. On the Possible Increasing of Efficiency of Ship Power Plant with the System Combined of marine Diesel Engine, Gas Turbine and Steam Turbine. Main Engine-Steam Turbine Mode of Cooperation. Pol. Marit. Res. 2009, 16, 47-52. [CrossRef] 
13. Akiliu, B.T.; Gilani, S.I. Mathematical Modelling and Simulation of a Cogeneration Plant. Appl. Therm. Eng. 2010, 30, 2545-2554. [CrossRef]

14. Dimopopulos, G.G.; Kakalis, N.M.P. An Integrated Modelling framework for the Design Operation and Control of Marine Energy Systems. In Proceedings of the CIMAC Congress, Bergen, Norway, 14-17 June 2010.

15. Grimmelius, H.; Boonen, E.J.; Nicolai, H.; Stapersma, D. The integration of Mean value First Principle Diesel Engine models in Dynamic Waste Heat and Cooling Load Analysis. In Proceedings of the CIMAC Congress, Bergen, Norway, 14-17 June 2010; Paper No. 280.

16. Theotokatos, G.; Livanos, G.A. Exhaust gas waste heat recovery in marine propulsion plants. In Proceedings of the 14th International Conference on Maritime Association of Mediterranean (IMAM 2011), Genova, Italy, 13-16 September 2011.

17. Byung, C.C.; Young, M.K. Thermodynamic analysis of a dual loop heat recovery system with trilateral cycle applied to exhaust gases of internal combustion engine for propulsion of the 6800 TEU container ship. Energy 2013, 58, 404-416.

18. Benvenuto, G.; Campora, U.; Trucco, A. Optimization of Waste Heat Recovery from the Exhaust Gas of Marine Diesel Engines. J. Eng. Marit. Environ. 2016, 230, 83-94. [CrossRef]

19. Benvenuto, G.; Campora, U.; Laviola, M.; Zaccone, R. Comparison of Waste Heat Recovery Systems for the Refitting of a Cruise Ferry. In Proceedings of the NAV 2015, 18th International Conference on Ships and Shipping Research, Lecco, Italy, 24-26 June 2015; pp. 404-415.

20. Altosole, M.; Benvenuto, G.; Campora, U.; Laviola, M.; Zaccone, R. Simulation and performance comparison between diesel and natural gas engines for marine applications. J. Eng. Marit. Environ. 2017, 231, 690-704. [CrossRef]

21. Livanos, G.A.; Theotokatos, G.; Patagonis, D.N. Techno-Economical Investigation of Alternative Propulsion Plant for Ferries and RoRo Ships. Energy Convers. Manag. 2014, 79, 640-651. [CrossRef]

22. Altosole, M.; Campora, U.; Laviola, M.; Zaccone, R. Waste Heat Recovery from Dual-Fuel Marine Engine; Soares, G., Benvenuto, T.G., Eds.; Taylor \& Francis Group: London, UK, 2018; ISBN 978-0-8153-7993-5.

23. Keiichi, S.; Yoshihisa, O. Hybrid Turbocharger with Integrated High Speed Motor-Generator; Technical Review; Mitsubishi Heavy Industries: Tokyo, Japan, 2007; Volume 44, pp. 1-3.

24. Keiichi, S.; Yoshihisa, O.; Kiyoko, S. Development of Large Marine Hybrid Turbocharger for Generating Electric Power with Exhaust Gas from the Main Engine; Mitsubishi Heavy Industries: Tokyo, Japan, 2010; Volume 47, pp. 53-58.

25. Yoshihisa, O.; Keiichi, S.; Yukio, Y. Application of a Large Hybrid Turbocharger for Marine Electric-Power Generation; Mitsubishi Heavy Industries: Tokyo, Japan, 2012; Volume 47, pp. $29-33$.

26. Keiichi, S.; Venky, K. Electro-Assist Turbo for Marine Turbocharger Diesel Engines. In Proceedings of the ASME Turbo Expo 2014, Turbine Conference and Exposition, Düsseldorf, Germany, 16-20 June 2014. [CrossRef]

27. Keiichi, S.; Yoshihisa, O.; Yukio, Y.; Musashi, S. Energy Savings Through Electric-Assist Turbocharger for Marine Diesel Engines; Mitsubishi Heavy Industries: Tokyo, Japan, 2015; Volume 52, pp. 36-41.

28. World's First Hybrid Turbocharged Bulk Carrier. The Motor Ship 2011. Available online: http:/ /www.mo torship.com/news101/ships-and-shipyards / worlds-first-hybrid-turbocharged-bulk-carrier (accessed on 17 July 2018).

29. Benvenuto, G.; Campora, U.; Laviola, M.; Terlizzi, G. Simulation Model of a Dual-Fuel Four Stroke Engine for Low Emission Ship Propulsion Applications. Int. Review Mech. Eng. 2017, 11, 817-824. [CrossRef]

30. Boveri, A.; D’Agostino, F.; Fidigatti, A.; Ragani, E.; Silvestro, F. Dynamic Modeling of a Supply Vessel Power System for DP3 Protection System. IEEE Trans. Transp. Electrification 2016, 2, 570-579. [CrossRef]

31. MAN 51/60 DF IMO TIER II/IMO TIER III, Project Guide-Marine, 2015. Available online: https:/ / marine.man-es.com/docs/default-source/shopwaredocuments / man-151-60df8f6b0c4947 39478a818ef2765bdbaa92.pdf?sfvrsn=6 (accessed on 17 July 2018).

(C) 2018 by the authors. Licensee MDPI, Basel, Switzerland. This article is an open access article distributed under the terms and conditions of the Creative Commons Attribution (CC BY) license (http:/ / creativecommons.org/licenses/by/4.0/). 